\title{
Proliferating Erythroid Cell to Total Cell Ratio Measurement
}

National Cancer Institute

\section{Source}

National Cancer Institute. Proliferating Erythroid Cell to Total Cell Ratio Measurement. NCl Thesaurus. Code C127632.

The determination of the ratio of proliferating erythroid cells compared to total cells present in a sample. The measurement may be expressed as a ratio or percentage. 